\title{
SCIDOC
}

International Journal of Dentistry and Oral Science (IJDOS)

ISSN: 2377-8075

\section{Association of Residual Ridge Resorption with Age, Gender and Underlying Medical Conditions in Completely Edentulos Patients - A Retrospective Study}

Research Article

Godlin Jeneta J ${ }^{1}$, Subhashree. $\mathrm{R}^{2 *}$, Nivedhitha M.S ${ }^{3}$

${ }^{1}$ Saveetha Dental College and Hospital, Saveetha Institute of Medical and Technical Sciences, Saveetha University, Chennai, India.

${ }^{2}$ Senior lecturer, Department of Prosthodontics, Saveetha Dental College and Hospital, Saveetha Institute of Medical and Technical Sciences, Saveetha University, Chennai, India.

${ }^{3}$ Professor, Dept of Conservative Dentistry \& Endodontics, Saveetha Dental College and Hospital, Saveetha Institute of Medical and Technical Sciences, Saveetha University, Chennai, India.

\section{Abstract}

Residual ridge resorption is based on multifactorial problem. This study aimed to assess the association between the age, gender, medical complications of the completely edentulism patient with the period of edentulism and the rate of residual ridge resorption. A total of 421 patients with completely edentulism status was selected in this study. The data were extracted from the digital software attending in a private hospital setup. The data extracted were based on the inclusion and exclusion criteria of the study. Most of the study population where male than females. The period of edentulism were between 2-5 years and more than 5 years. The residual ridge resorption was assessed based on the clinical photographs and radiographs. The results of the study revealed that there is a significant association of age, gender, medical complication, period of edentulism and ridge resorption with a $\mathrm{p}$ value of $<0.5$. The results of the present study revealed that, most of the completely edentulism patient above 60 years had more medical complication, ridge resorption and period of edentulism. Males had more medical complications, ridge resorption than females. Ridge resorption is associated with the underlying medical complications and the period of edentulism. Better understanding of the medical history of the patient can determine the residual ridge resorption pattern.

\section{Introduction}

The bone tends to resorb when the tooth is removed which leads to residual ridge resorption. The pattern of resorption varies from maxilla to mandible, the maxillary width reduces whereas the mandibular width widens [2]. The resorption rate is rapid during the initial stage after extraction. The rate of resorption is more in maxilla than in mandible due the quality of the bone [36]. The resorption of the ridge occurs from the labial cortical plate to lingual and eventually leads to the knife edged pattern of the ridge followed by low well rounded [15]. Alveolar ridge bounds the teeth in all directions and acts as an anchor to the teeth(tencate). The stages of ridge resorption is characterised by Atwood as six orders. The initial order if before extraction, order 2 is post extraction, order 3 is high well rounded, order 4 is knife edged, order 5 is low well rounded and order 6 is depressed.
These sarges of ridge resorption occur at different times after a tooth is removed [14].

The term for ridge resorption is residual ridge resorption (RRR) given by Atwood. It is a chronic, progressive and cumulative pattern of disease of the bone. The amount of RRR varies at different age groups and has multiple factors[29]. A severe RRR always leads to improper construction of the complete denture in completely edentulous patients and the treatment planning will become quite challenging to the dentist.

There are many factors for RRR and can be divided into two categories mainly: local factors and systemic factors. The quality, anatomy, size and shape of the ridge is categorised under localised factors whereas age, gender, systemic conditions, habits are categorised under systemic factors $[15,10]$. During the menopause

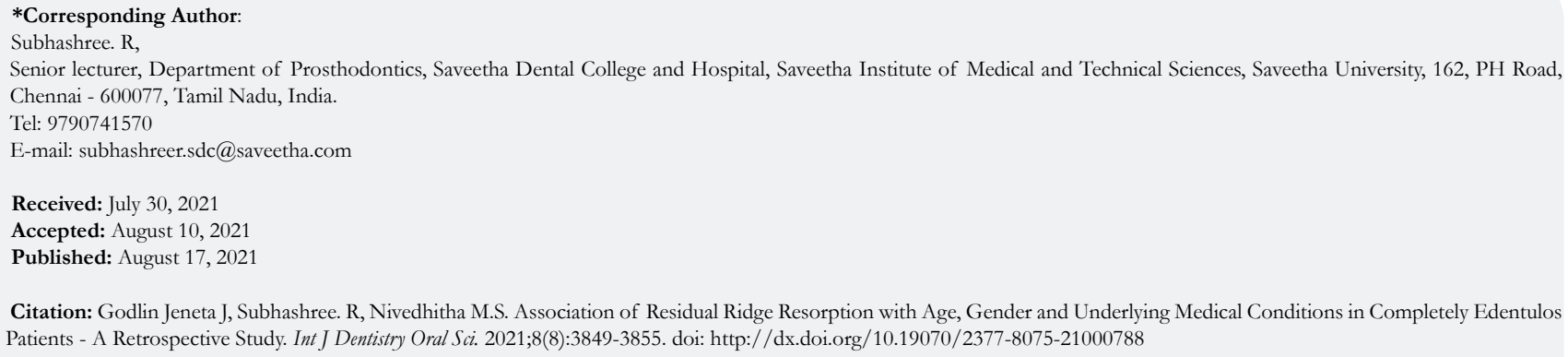

Citation: Godlin Jeneta J, Subhashree. R, Nivedhitha M.S. Association of Residual Ridge Resorption with Age, Gender and Underlying Medical Conditions in Completely Edentulos Patients - A Retrospective Study. Int J Dentistry Oral Sci. 2021;8(8):3849-3855. doi: http://dx.doi.org/10.19070/2377-8075-21000788

Copyright: Subhashree. $\mathbf{R}^{\circ} 2021$. This is an open-access article distributed under the terms of the Creative Commons Attribution License, which permits unrestricted use, distribution and reproduction in any medium, provided the original author and source are credited. 
the oestrogen deficiency accelerates and leads to generalised mineral loss to the women. This loss of bone mass leads to RRR. The mandibular ridge resorption is more common in women than in men. Likewise, systemic factors also lead to RRR . Patients with osteoporosis encounter severe RRR with low bone density, thinning of the cortical plate. Many underlying systemic conditions like thyroid, hypertension, diabetes are the risk factors for osteoporosis and may lead to severe RRR. Habits such as alcoholism leads to deleterious effects on bone structure. Smoking is also a major risk factor for bone fracture and bone loss. Smoking and many periodontal diseases have an association and have been proved by many studies.

RRR may also occur with patients wearing dentures for a long period of time and patients with long term edentulism. There are many studies which have measured the RRR with different devices like cephalometric, OPG, calliper and VAS. Wical and Swoope determined initially with the help of orthopantomographic (OPG) $[3,4,16]$. OPG were used to analyze the location of different anatomical structures especially mental foramen with relation to the crestal level of the bone by many researchers to study the pattern of RRR according to different ages of the patients. Knowing the aetiology, metabolic factor, anatomical factor, systemic factor, pathogenesis of resorption, and the histological factors are available in the literature. However, there is a little knowledge in the association of age, period of edentulous, the systemic condition in association to the residual ridge resorption in the literature.

Previously our team has a rich experience in working on various research projects across multiple disciplines $[18,17,26,13,9,7$, $21,27,20,5,37,1,11,31,33]$. Now the growing trend in this area motivated us to pursue this project.

This study aims to assess the association between the different medical conditions, age gender of the completely edentulous patient and the rate of bone resorption seen clinically which will aid in proper treatment planning knowing the medical condition of the patients.

\section{Materials And Methods}

A single centre retrospective study was done in an institutional setting. The ethical approval was received from the institution's ethical committee. The study involved selected patients data who were completely edentulous and had undergone complete denture. The necessary approvals in gaining the datas were obtained from the institutional ethical committee (SDC/SIHEC/DIAS-
DATA/0619-0320). The number of people involved in this study includes 3 i.e guide, reviewer and researcher.

\section{Selection of subjects:}

All patients who had undergone in completely edentulous and had undergone complete denture from the time period of June 2019 to April 2020 were selected for this study. There were three people involved in this study (guide, reviewer, and researcher). All available data were taken into consideration and there was no sorting process.

\section{Data collection:}

The patient's details were retrieved from the institution's patient record management software (Dental Information Archiving Software). Data regarding patients age, gender, medical condition, period of edentulism were taken into consideration for this study. Cross verification of the data was done with the help of photographs and radiographs. The data was manually verified, tabulated and sorted.

\section{Inclusion Criteria:}

All patients were completely edentulous and had undergone complete denture. All age groups were taken into account.

\section{Exclusion Criteria:}

Patients' records that were incomplete were removed from the study. Repetitive entries were excluded as well.

\section{Statistical Analysis:}

The tabulation of data was analysed using SPSS software. (IBM SPSS Statistics 26.0) The method of statistical analysis that was used in this study was Chi Square Test to compare two proportions. The analysis was done for: age, gender, medical condition, period of edentulism in this study.

\section{Results \& Discussion}

The total population of the study was 421 . The age distribution of the present study population is as follows $-11.16 \%$ were between $30-50$ years of age , $26.60 \%$ were between $50-60$ years of age and $62.23 \%$ were above 60 years of age (figure 1 ). In our study, $59.89 \%$ were males whereas $40.14 \%$ were females (figure 2 ). The

Figure 1: Shows the age distribution of the completely edentulous patients. $\mathrm{X}$ axis represents the age of the completely edentulous patient and $\mathrm{Y}$ axis represents the number of patients with complete denture. $11.16 \%$ were between $30-50$ years of age (red), $26.60 \%$ were between $50-60$ years of age (green) and $62.23 \%$ were above 60 years of age (blue).

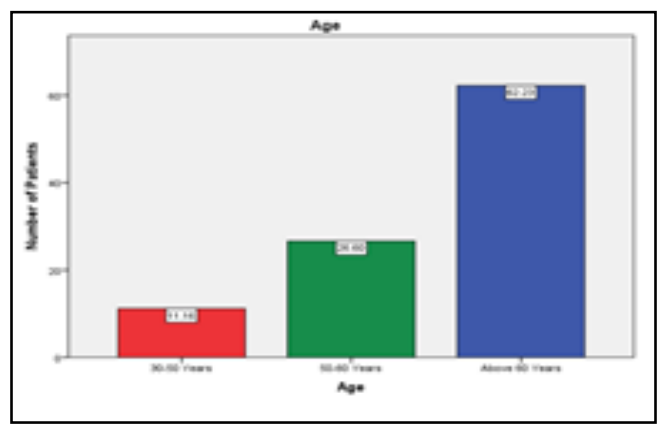


medical complications associated with the edentulous patient in the present study revealed that $18.53 \%$ had hypertension, $26.37 \%$ had diabetes, $4.513 \%$ had Asthma, $8.797 \%$ had other systemic conditions, and $41.81 \%$ were disease free (figure 3 ). The edentulism status of the present study revealed that $24.70 \%$ had $<$ than 1 year, $39.67 \%$ had $2-5$ years, and $35.63 \%$ had $>5$ years of period of edentulism (figure 4). The resorption status of the study revealed that $38 \%$ of the population had ridge resorption and $62 \%$ did not have ridge resorption (figure 5).

The association between the age and the medical complications revealed that $0.95 \%, 9.89 \%, 7.60 \%$ of hypertension was seen in the age group of 30-50 years, 50-60 years, above 60 years respectively. $0.41 \%, 4.04 \%, 21.62 \%$ of diabetes were seen in the age group of 30-50 years, 50-60 years, above 60 years respectively. $1.43 \%, 3.09 \%$ of Asthma were seen in the age group of $50-60$ years, above 60 years respectively. $1.66 \%, 0.71 \%, 6.41 \%$ of other complications were seen in the age group of 30-50 years, 50-60 years, above 60 years respectively. $7.84 \%, 10.45 \%, 23.52 \%$ of no medical complications were seen in the age group of 30-50 years, 50-60 years, above 60 years respectively. Chi square association was done and found to be statistically significant. Chi square value: 69.440 , df value: 8 , p value: $0.03(<0.05)$ (figure 6$)$.

The association between the age and ridge resorption revealed that $1.66 \%, 12.83 \%, 23.52 \%$ of the patient between the age group of $30-50$ years, $50-60$ years, above 60 years respectively had residual ridge resorption whereas $9.50 \%, 13.78 \%, 38.72 \%$ of the patient between the age group of 30-50 years, 50-60 years, above 60 years respectively had no residual ridge resorption. Chi square association was done and found to be statistically significant. Chi square value: 15.615 , df value: 2 , p value: $0.000(<0.05)$ (figure 7 ).

The association between the age and period of edentulism re-

Figure 2: Shows the gender distribution of the completely edentulous patients. $\mathrm{X}$ axis represents the gender of the completely edentulous patient and $\mathrm{Y}$ axis represents the number of patients with complete denture. $59.89 \%$ were males (blue) whereas $40.14 \%$ were females (red).

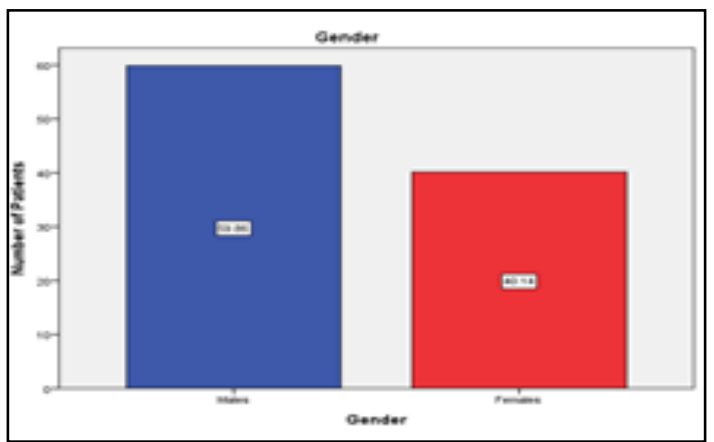

Figure 3: Shows the distribution of the medical complications of the completely edentulous patients. $\mathrm{X}$ axis represents the medical complications of the completely edentulous patient and Y axis represents the number of patients with complete denture. 18.53\% had hypertension (red), 26.37\% had diabetes (green), 4.513\% had Asthma (blue), 8.797\% had other systemic conditions (yellow), and 41.81\% were disease free (grey).

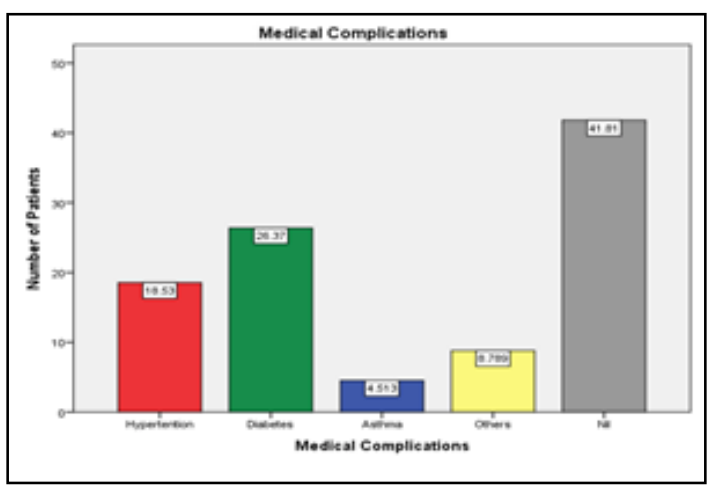

Figure 4: Shows the distribution of the period of edentulism of the completely edentulous patients. $\mathrm{X}$ axis represents the period of edentulism of the completely edentulous patient and $\mathrm{Y}$ axis represents the number of patients with complete denture. $24.70 \%$ had $<$ than 1 year (red), $39.67 \%$ had $2-5$ years (green), and $35.63 \%$ had $>5$ years of period of edentulism.

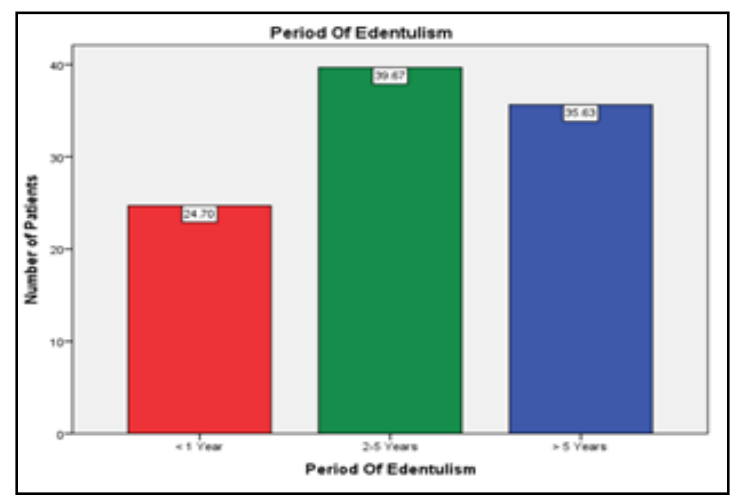


Figure 5: Shows the distribution of the presence of ridge resorption of the completely edentulous patients. $\mathrm{X}$ axis represents the presence of ridge resorption of the completely edentulous patient and $\mathrm{Y}$ axis represents the number of patients with complete denture. $38 \%$ of the population had ridge resorption (red) and $62 \%$ did not have ridge resorption (blue).

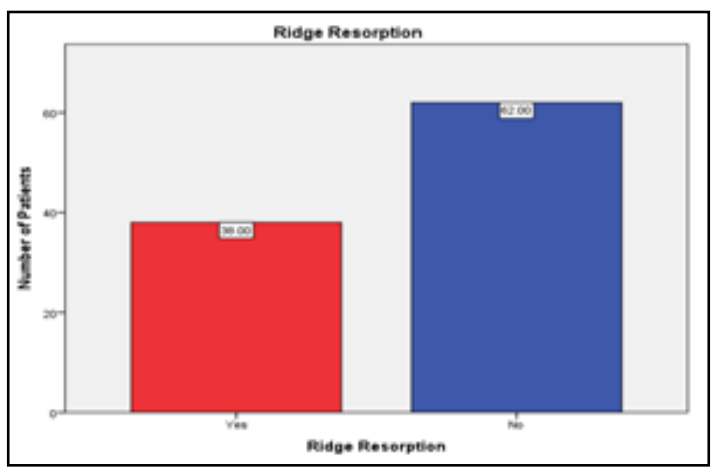

Figure 6: Shows the association between the age of the completely edentulous patient and the medical complications (hypertension, diabetes, asthma, others, nil). $\mathrm{X}$ axis represents the age of the patients and $\mathrm{Y}$ axis represents the number of patients with complete dentures. Chi square association was done and found to be statistically significant. Chi square value: 69.440 , df value: 8 , p value: 0.03 ( $<0.05$ ), hence proving that more medical problems are prevalent in the older age group and diabetes is the most common medical condition among denture wearers.

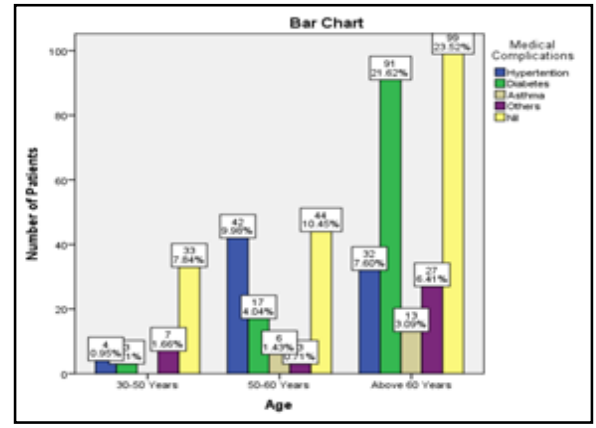

Figure 7. Shows the association between the age of the completely edentulous patient and the prevalence of ridge resorption. $\mathrm{X}$ axis represents the age of the patients and $\mathrm{Y}$ axis represents the number of patients with complete denture with ridge resorption. Chi square association was done and found to be statistically significant. Chi square value: 15.615 , df value: 2 , p value: $0.000(<0.05)$, hence proving denture wearers above 60 years of age reported with less ridge resorption than other age groups.

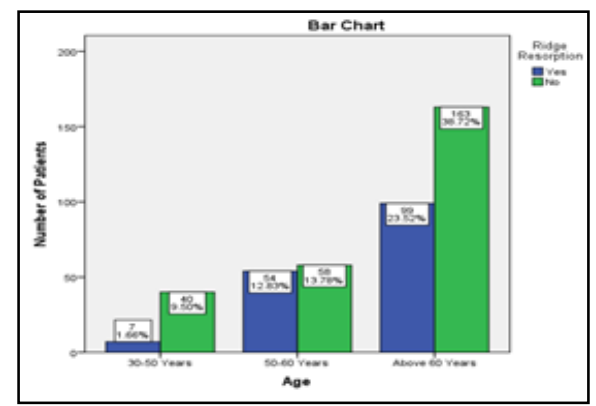

Figure 8. Shows the association between the age of the completely edentulous patient and the period of edentulism. $\mathrm{X}$ axis represents the age of the patients and $\mathrm{Y}$ axis represents the number of patients with complete denture with period of edentulism. Chi square association was done and found to be statistically significant. Chi square value: 186.032 , df value: 4 , p value: $0.020(<0.05)$, hence proving as the age increases the period of edentulism increases and more than 5 years is seen above 60 years.

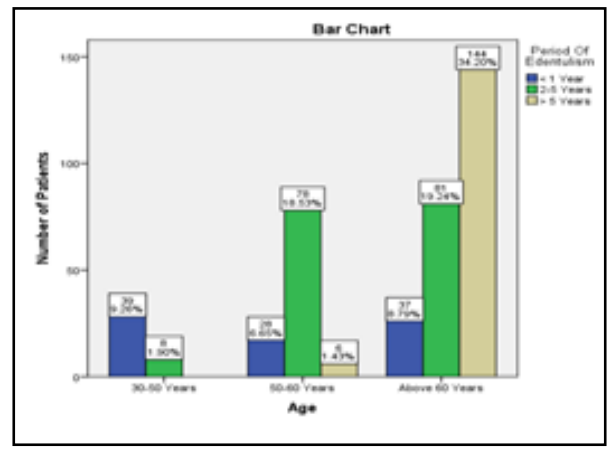


veals that $9.26 \%, 6.65 \%, 8.79 \%$ had less than 1 years of period of edentulism within the age group of 30-50 years, 50-60 years, and above 60 years respectively. $1.90 \%, 18.53 \%, 19.24 \%$ of the completely edentulous patients had 2- 5 years of period of edentulism within the age group of 30-50 years, 50-60 years, and above 60 years respectively. $1.43 \%, 34.20 \%$ of the completely edentulous patients had more than 5 myears of period of edentulism within the age group of 50-60 years, and above 60 years respectively. Chi square association was done and found to be statistically significant. Chi square value: 186.032 , df value: 4, p value: 0.020 ( < 0.05) (figure 8)

The association between the gender and the medical complications revealed that $13.05 \%, 5.46 \%$, of hypertension was seen in males and females respectively. $15.91 \%, 10.45 \%$ of diabetes were seen in males and females respectively. 1.19\%, 3.33\% of Asthma were seen in males and females respectively. $5.23 \%, 3.56 \%$ of other complications were seen in males and females respectively. $24.47 \%, 17.34 \%$ of no medical complications were seen in males and females respectively. Chi square association was done and found to be statistically significant. Chi square value: $12.726 \mathrm{df}$ value: 4 , $\mathrm{p}$ value: $0.013(<0.05)$ ( figure 9$)$.

The association between the gender and ridge resorption revealed that $23.75 \%, 14.25 \%$ had ridge resorption between the males and females respectively. $36.10 \%, 25.89 \%$ had no ridge resorption between males and females respectively. Chi square association was done and found to be statistically not significant. Chi square value: 0.750 , df value: 1 , p value: 0.383 ( > 0.05) (figure 10).

The association between the gender and period of edentulism reveals that $10.45 \%, 14.25 \%$ of males and females had less than
1 years of period of edentulism respectively. $19.71 \%, 19.95 \%$ of males and females had 2- 5 years of period of edentulism $29.69 \%$, $5.94 \%$ of males and females had more than 5 years of period of edentulism. Chi square association was done and found to be statistically significant. Chi square value: 54.905 , df value: 2 , p value: $0.00(<0.05)$ ( figure 11).

The association between the medical complication and the prevalence of ridge resorption revealed that $7.36 \%, 13.30 \%, 2.61 \%$ $10.93 \%$ of patients with hypertension, diabetes, asthma, others, nil respectively had residual ridge resorption whereas $11.16 \%$, $13.06 \%, 1.90 \%, 30.88 \%$ of patients with hypertension, diabetes, asthma, others, nil respectively had no residual ridge resorption. Chi square association was done and found to be statistically significant. Chi square value: 21.541 , df value: 4 , p value: 0.034 (< 0.05) ( figure 12).

The association between period of edentulism of the completely edentulous patient and the prevalence of ridge resorption revealed that $5.23 \% 12.59 \%, 20.19 \%$ had ridge resorption with $<1$ year, $2-5$ years, and $>5$ years $\hat{A}$ of period of edentulism respectively. $19.48 \%, 27.08 \%, 15.44 \%$ had no ridge resorption with $<1$ year, 2-5 years, and $>5$ years Â of period of edentulism respectively. Chi square association was done and found to be statistically significant. Chi square value: 37.491 , df value: 2 , $\mathrm{p}$ value: 0.04 $(<0.05)$ (figure 13).

The study results showed that most of the residual ridge resorption is based on the underlying medical complications. hypertension, diabetes and asthma had residual ridge resorption. Similar study done by Atwood had found significant association between the medical complication and ridge resorption. In the present

Figure 9: Shows the association between the gender of the completely edentulous patient and the medical complications (hypertension, diabetes, asthma, others, nil). $\mathrm{X}$ axis represents the gender of the patients and $\mathrm{Y}$ axis represents the number of patients with complete denture. Chi square association was done and found to be statistically significant. Chi square value: 12.726 , df value: 4 , p value: 0.013 ( $<0.05)$, hence proving that more number of male denture wearers had medical conditions (diabetes, hypertension) than females.

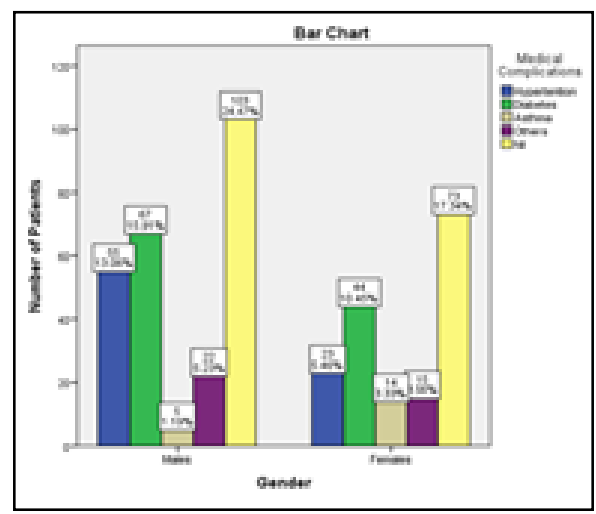

Figure 10: Shows the association between the gender of the completely edentulous patient and the prevalence of ridge resorption. $\mathrm{X}$ axis represents the gender of the patients and $\mathrm{Y}$ axis represents the number of patients with complete denture with ridge resorption. Chi square association was done and found to be statistically not significant. Chi square value: 0.750 , df value: $1, \mathrm{p}$ value: 0.383 ( $>0.05$ ), however more number of males had alveolar ridge resorption than females.

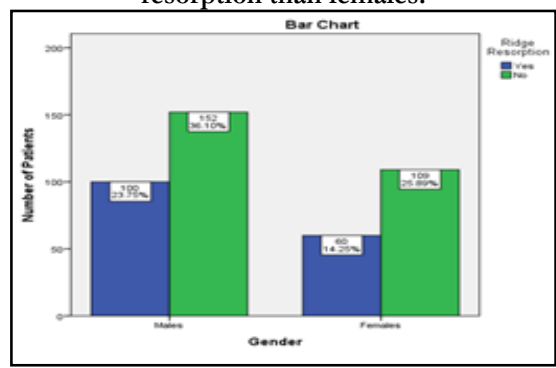


Figure 11: Shows the association between the gender of the completely edentulous patient and the period of edentulism. $\mathrm{X}$ axis represents the gender of the patients and $\mathrm{Y}$ axis represents the number of patients with complete denture with period of edentulism. Chi square association was done and found to be statistically significant. Chi square value: 54.905 , df value: 2 , p value: $0.00(<0.05)$, hence proving that more number of males were edentulous for a longer period of time $(>5 \mathrm{yrs})$ than females.

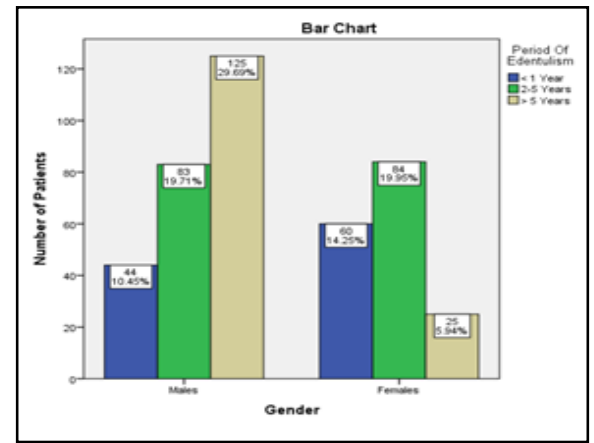

Figure 12: Shows the association between the medical complications of the completely edentulous patient and the prevalence of ridge resorption. $\mathrm{X}$ axis represents the medical complications of the patients and $\mathrm{Y}$ axis represents the number of patients with complete denture with ridge resorption. Chi square association was done and found to be statistically significant. Chi square value: 21.541 , df value: 4 , $p$ value: 0.034 (< 0.05$)$, proving that more ridge resorption occurs with underlying medical complications (hypertension, diabetes, asthma).

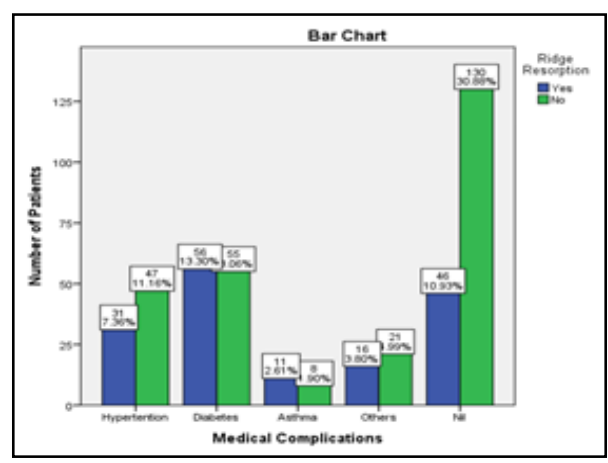

Figure 13: Shows the association between the period of edentulism of the completely edentulous patient and the prevalence of ridge resorption. $X$ axis represents the period of edentulism of the patients and $\mathrm{Y}$ axis represents the number of patients with complete denture with ridge resorption. Chi square association was done and found to be statistically significant. Chi square value: 37.491 , df value: 2 , p value: 0.04 ( $<0.05$ ), proving that ridge resorption was more common among the patients with longer duration of edentulism.

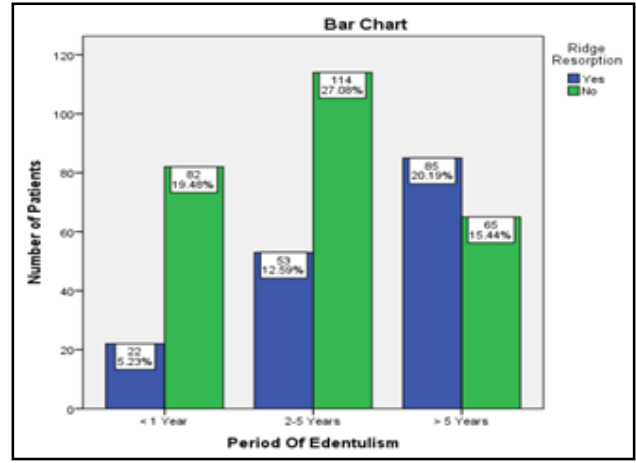

study $2.61 \%$ had residual ridge resorption, this may be due to the consumption of the corticosteroids which reduces the quality of the bone. Many researchers have proved that there is an association between asthma and bone resorption [35].

In the present study the males had more residual resorption than females, however it was statistically significant. Females are subjected to the risk factor of osteoporosis after menopause stage[34]. Many studies have shown that the oestrogen deficiency affects the rate of resorption. The period of edentulism also is associated with residual ridge resorption. In our present study it is shown that the rate of resorption is predominantly seen in the patients with more than 5 years of edentulism. One of the studies done by Lopez proved that if the bone undergoes atrophy over a period of time due to not being in use, there will not be any remodelling of bone occuring [30].

Our institution is passionate about high quality evidence based research and has excelled in various fields $[19,20,8,22,28,32,6$, $12,24,25]$. We hope this study adds to this rich legacy.

\section{Conclusion}

The results of the present study revealed that, most of the completely edentulous patients above 60 years had more medical conditions and were edentulous for a longer period of time without opting for dentures. More number of males were edentulous for a longer duration,had medical conditions and ridge resorption 
than females. Ridge resorption was associated with the underlying medical conditions and the duration of edentulism.

\section{References}

[1]. Manohar T, Santhanam A. Correlation between bizygomatic and maxillary central incisor width for gender identification. Brazilian Dent Sci. 2019 Oct 31;22(4):458-66

[2]. Atwood DA. Some clinical factors related to rate of resorption of residual ridges. 1962. J Prosthet Dent. 2001 Aug;86(2):119-25. PMID: 11514795.

[3]. Atwood DA. Reduction of residual ridges: a major oral disease entity. J Prosthet Dent. 1971 Sep;26(3):266-79. PMID: 4934947.

[4]. Atwood DA, Coy WA. Clinical, cephalometric, and densitometric study of reduction of residual ridges. J Prosthet Dent. 1971 Sep;26(3):280-95. doi: 10.1016/0022-3913(71)90070-9. PMID: 5284182.

[5]. Azeem RA, Sureshbabu NM. Clinical performance of direct versus indirect composite restorations in posterior teeth: A systematic review. J Conserv Dent. 2018 Jan-Feb;21(1):2-9. Pubmed PMID: 29628639.

[6]. Chandrasekar R, Chandrasekhar S, Sundari KKS, Ravi P. Development and validation of a formula for objective assessment of cervical vertebral bone age. Prog Orthod. 2020 Oct 12;21(1):38. Pubmed PMID: 33043408.

[7]. Chen F, Tang Y, Sun Y, Veeraraghavan VP, Mohan SK, Cui C. 6-shogaol, a active constiuents of ginger prevents UVB radiation mediated inflammation and oxidative stress through modulating $\mathrm{NrF} 2$ signaling in human epidermal keratinocytes (HaCaT cells). J Photochem Photobiol B. 2019 Aug;197:111518. Pubmed PMID: 31202076.

[8]. Ezhilarasan D, Apoorva VS, Ashok Vardhan N. Syzygium cumini extract induced reactive oxygen species-mediated apoptosis in human oral squamous carcinoma cells. J Oral Pathol Med. 2019 Feb;48(2):115-121 Pubmed PMID: 30451321

[9]. Govindaraju L, Neelakantan P, Gutmann JL. Effect of root canal irrigating solutions on the compressive strength of tricalcium silicate cements. Clin Oral Investig. 2017 Mar;21(2):567-571. Pubmed PMID: 27469101.

[10]. Jeffcoat MK, Chesnut CH 3rd. Systemic osteoporosis and oral bone loss: evidence shows increased risk factors. J Am Dent Assoc. 1993 Nov;124(11):4956. Pubmed PMID: 8227773.

[11]. Manohar J. A Study on the Knowledge of Causes and Prevalance of Pigmentation of Gingiva among Dental Students. Indian Journal of Public Health Research \& Development. 2019 Aug 1;10(8).

[12]. Mathew MG, Samuel SR, Soni AJ, Roopa KB. Evaluation of adhesion of Streptococcus mutans, plaque accumulation on zirconia and stainless steel crowns, and surrounding gingival inflammation in primary molars: randomized controlled trial. Clin Oral Investig. 2020 Sep;24(9):3275-3280. Pubmed PMID: 31955271.

[13]. Muthukrishnan A, Warnakulasuriya S. Oral health consequences of smokeless tobacco use. Indian J Med Res. 2018 Jul;148(1):35-40. Pubmed PMID: 30264752 .

[14]. Nishimura I, Damiani PJ, Atwood DA. The reduction of residual ridges (RRR) measured longitudinally in rats. J Prost Dent. 1986 Jan 1;55(1):133.

[15]. Nishimura I, Hosokawa R, Atwood DA. The knife-edge tendency in mandibular residual ridges in women. J Prosthet Dent. 1992 Jun;67(6):820-6. Pubmed PMID: 1403869.

[16]. Oikarinen K, Raustia AM, Hartikainen M. General and local contraindications for endosseal implants--an epidemiological panoramic radiograph study in 65-year-old subjects. Community Dent Oral Epidemiol. 1995 Apr;23(2):114-8. Pubmed PMID: 7781299

[17]. Palati S, Ramani P, Shrelin HJ, Sukumaran G, Ramasubramanian A, Don KR, Jayaraj G, Santhanam A. Knowledge, Attitude and practice survey on the perspective of oral lesions and dental health in geriatric patients residing in old age homes. Indian J Dent Res. 2020 Jan-Feb;31(1):22-25. Pubmed PMID: 32246676

[18]. Paramasivam A, Vijayashree Priyadharsini J, Raghunandhakumar S. N6adenosine methylation (m6A): a promising new molecular target in hypertension and cardiovascular diseases. Hypertens Res. 2020 Feb;43(2):153154. Pubmed PMID: 31578458.

[19]. J PC, Marimuthu T, C K, Devadoss P, Kumar SM. Prevalence and measurement of anterior loop of the mandibular canal using CBCT: A cross sectional study. Clin Implant Dent Relat Res. 2018 Aug;20(4):531-534. Pubmed PMID: 29624863

[20]. Vijayashree Priyadharsini J, Smiline Girija AS, Paramasivam A. In silico analysis of virulence genes in an emerging dental pathogen A. baumannii and related species. Arch Oral Biol. 2018 Oct;94:93-98. Pubmed PMID: 30015217.

[21]. Priyanka S, Kaarthikeyan G, Nadathur JD, Mohanraj A, Kavarthapu A Detection of cytomegalovirus, Epstein-Barr virus, and Torque Teno virus in subgingival and atheromatous plaques of cardiac patients with chronic periodontitis. J Indian Soc Periodontol. 2017 Nov-Dec;21(6):456-460. Pubmed PMID: 29551863

[22]. Ramadurai N, Gurunathan D, Samuel AV, Subramanian E, Rodrigues SJL. Effectiveness of $2 \%$ Articaine as an anesthetic agent in children: randomized controlled trial. Clin Oral Investig. 2019 Sep;23(9):3543-3550. Pubmed PMID: 30552590

[23]. Ramesh A, Varghese S, Jayakumar ND, Malaiappan S. Comparative estimation of sulfiredoxin levels between chronic periodontitis and healthy patients - A case-control study. J Periodontol. 2018 Oct;89(10):1241-1248. Pubmed PMID: 30044495.

[24]. R H, Ramani P, Ramanathan A, R JM, S G, Ramasubramanian A, K M. CYP2 C9 polymorphism among patients with oral squamous cell carcinoma and its role in altering the metabolism of benzo[a]pyrene. Oral Surg Oral Med Oral Pathol Oral Radiol. 2020 Sep;130(3):306-312. Pubmed PMID: 32773350.

[25]. Samuel SR. Can 5-year-olds sensibly self-report the impact of developmental enamel defects on their quality of life? Int J Paediatr Dent. 2021 Mar;31(2):285-286. Pubmed PMID: 32416620.

[26]. Samuel SR, Acharya S, Rao JC. School Interventions-based Prevention of Early-Childhood Caries among 3-5-year-old children from very low socioeconomic status: Two-year randomized trial. J Public Health Dent. 2020 Jan;80(1):51-60. Pubmed PMID: 31710096.

[27]. Sitharthan R, Sundarabalan CK, Devabalaji KR, Yuvaraj T, Mohamed Imran A. Automated power management strategy for wind power generation system using pitch angle controller. Measurement and Control. 2019 Mar;52(3-4):169-82

[28]. Sridharan G, Ramani P, Patankar S, Vijayaraghavan R. Evaluation of salivary metabolomics in oral leukoplakia and oral squamous cell carcinoma. J Oral Pathol Med. 2019 Apr;48(4):299-306. Pubmed PMID: 30714209.

[29]. Steidler NE, Cook RM, Reade PC. Residual complications in patients with major middle third facial fractures. Int J Oral Surg. 1980 Aug;9(4):259-66. Pubmed PMID: 6780474

[30]. Swoope CC. Complete denture prosthodontics--1998. J Prosthet Dent 1974 Oct;32(4):383-90. Pubmed PMID: 4528483.

[31]. Venu H, Raju VD, Subramani L. Combined effect of influence of nano additives, combustion chamber geometry and injection timing in a DI diesel engine fuelled with ternary (diesel-biodiesel-ethanol) blends. Energy. 2019 May 1;174:386-406.

[32]. Vijayashree Priyadharsini J. In silico validation of the non-antibiotic drugs acetaminophen and ibuprofen as antibacterial agents against red complex pathogens. J Periodontol. 2019 Dec;90(12):1441-1448. Pubmed PMID: 31257588.

[33]. Wang Y, Zhang Y, Guo Y, Lu J, Veeraraghavan VP, Mohan SK, Wang C, $\mathrm{Yu}$ X. Synthesis of Zinc oxide nanoparticles from Marsdenia tenacissima inhibits the cell proliferation and induces apoptosis in laryngeal cancer cells (Hep-2). J Photochem Photobiol B. 2019 Dec;201:111624. Pubmed PMID: 31722283.

[34]. Watson EL, Katz RV, Adelezzi R, Gift HC, Dunn SM. The measurement of mandibular cortical bone height in osteoporotic vs. non-osteoporotic postmenopausal women. Spec Care Dentist. 1995 May-Jun;15(3):124-8. Pubmed PMID: 8619174

[35]. Wical KE, Swoope CC. Studies of residual ridge resorption. II. The relationship of dietary calcium and phosphorus to residual ridge resorption. J Prosthet Dent. 1974 Jul;32(1):13-22. Pubmed PMID: 4525508.

[36]. Wittkampf AR. Augmentation of the maxillary alveolar ridge with hydroxylapatite and fibrin glue. J Oral Maxillofac Surg. 1988 Nov;46(11):1019-21. Pubmed PMID: 3183802.

[37]. Wu F, Zhu J, Li G, Wang J, Veeraraghavan VP, Krishna Mohan S, Zhang Q. Biologically synthesized green gold nanoparticles from Siberian ginseng induce growth-inhibitory effect on melanoma cells (B16). Artif Cells Nanomed Biotechnol. 2019 Dec;47(1):3297-3305. Pubmed PMID: 31379212. 